\title{
Study on the Instruction of EOP
}

\section{Xixiang Ke and Xue Yang}

Wuhan Textile University, Wuhan, China 430070

1753270552@qq.com,2296204523@qq.com

\section{Keywords: EOP; Instruction; Follow-up course}

\begin{abstract}
This paper briefly introduces the current problems and characteristics of general English and ESP and analyzes the necessity of setting up English course for occupational purposes as one of the follow-up courses of college English. The necessity and practicality of English courses for occupational purposes included in college English curriculum are probed. Teaching characteristics, teaching content, teaching mode, teaching methods, assessment methods and other professional demands are explored in details in order to provide reference for improving the teaching quality of EOP, which further facilitates the effective implementation of college English curriculum. Teaching suggestions are offered afterwards.
\end{abstract}

\section{Introduction}

The recent guidelines for College English teaching have regarded ESP as one of the main contents of college English education [1], which reveals that the orientation of college English teaching in our country began to change, English for specific purposes eventually being an indispensable part of college English education.

With the constant change of the social demand for talent, cultivating practical talents is gradually becoming one of the important goals of higher education in our country. The requirement for foreign language talents in the society also transform from the foreign language professionals to professional foreign language talents. English as a well-received interlanguage of international communication, has almost become an essential skill of college students in employment.

The development and improvement of students' English level in secondary schools make it possible to set courses of EGAP, EGSP and EOP(English for Occupational Purposes) [2]. Traditional teaching that is largely confined to grammar, language structure, the appreciation of literature and general language proficiency test. As a result, inability to read business contract, interact with clients of different cultures or commercial documents make students less competitive in the job market. The present College English curriculum setting[3], which fail to meet the actual needs of the enterprise, should be reformed. The follow-up courses are to be explored and called into existence.

\section{Problems in current instruction of EOP}

EOP teaching[4], exam-oriented, places emphasis on problem analysis instead of information inputting, especially the absorbing of macro-economy, technique research instead of tactic reading, stick to convention instead of cultivating creative thinking.

Domestic and world economy, big data and fragmentation are interdependent. There is great demand for talents who excel in EOP while graduates tend to be unqualified due to their lack of subject cognitive thinking, a global horizon. Only by arousing the common initiative of teachers and students can we gradually get out of the predicament. If the competitive power of EOP graduates in the job market is ignored, they will lose its specific resource implications. Therefore, the significance of strengthening the cultivation of the subject cognitive thinking of teachers and students lies in the promotion of their value attributes. While the key to cultivate subject cognitive thinking is to strengthen teacher-student sensitivity to macro thinking so as to get rid of closed knowledge type and actively mobilize student-centered thinking potential. Only by expanding 
vision will students take the initiative to find the focus in occupation gradually, hence revise the cognitive concept.

\section{Teaching reform philosophy}

According to the research and analysis, foreign language teaching can exert influence on learners by fully reflecting relevance, satisfaction and integrity of learning needs. Taylor, a famous American educator and expert in curriculum theory perceive learners 'needs, the needs of contemporary social life and the development of disciplines are three sources of curriculum objectives.

EOP teaching reform should start with needs[5], personally and economically. EOP curriculum construction is supposed to be developed under the guide of professional education.

\section{Curriculum characteristics}

Innovation of teaching philosophy. The skills of English language learning and occupation training are organically integrated with the classification guidance and individualized principle in order to adapt to the actual needs of students' occupation and individualized learning. The teaching content is closely associated with specific profession with the aim of cultivating cultural exchanges and cooperation ability, cultivating students' cross cultural communication consciousness, improving the students' moral and cultural quality and enhancing students' core ability of occupation, which lay solid foundation for the development of students' occupation.

Professionalism of teaching design. The teaching design highlights the professionalism and the cultivation of students' English professional ability. Typical tasks occurring in occupation serve as teaching project and teaching activities. Students' hands-on practice is mainly focused in the teaching design featuring[6] the integration of project practice and group activities and other forms of language skills training with occupation expertise. Language knowledge learning and occupation quality training are involved. Input is combined with output, understanding with expression and experience with analysis. They are indicated in such ways as task activation, language input, language focus, language use, extended learning, culture and strategy.

Diversity of teaching content. The teaching content revolves around professional scenes, including English for General Purposes and English for Occupational Purposes. International general standards may act as teaching content.

Take business English for instance, cultural knowledge, cultural connotations of meaning, cross-cultural misunderstanding produced by cultural differences, cultural differences in business communication and management, business negotiation and business writing are indispensable part of teaching content.

Integration of learning tasks and typical professional tasks which serve as the center of teaching are necessary teaching content. The working process of learning tasks on the basis of enterprise workflow or scene design are considered valuable learning. Related functions and topics concerning occupations are systematically divided to cultivate professional English practical ability and meanwhile ensure the integration of language input and output. These functions, scenes and themes in different levels cycle for many times, and are gradually deepened in learners' minds.

Employment of teaching methods. A variety of flexible and varied teaching methods are exploited. Various teaching activities are implemented. Communication approach and task-based instruction[7], project-based instruction and role-play are employed with the specific task as the learning motivation, which help students learn something in the process of completing the task, fully exerting students' enthusiasm. The combination of formative assessment and terminal assessment ensure relatively reasonable evaluation of students with the purpose of measuring English application ability of students. Evaluation[8] can be students' self-assessment, group evaluation, teacher evaluation and other forms. 


\section{Teaching Suggestions}

A variety of ways to develop EOP curriculum are to be employed such as teaching approaches Content-based Instruction, Task-based Learning, Project-based Learning and Problem-based Instruction. The development path is as follows. Learners' English learning need analysis and social demand analysis come before refinement of typical business-related tasks, establishment of English learning situation, design of assignment and classroom teaching practice.

Short-term training is supposed to be started in order to target the improvement of specific skills, such as oral English for occupational purposes, thinking training, professional ritual training and related commercial law training. Such related subjects as commercial letter writing, peculiar culture of each country, business negotiation, logistics are also of significance to enrich students' perception of EOP and enhance comprehension of EOP. There is a great demand for relevant training and subjects to improve the teaching quality of EOP.

Industry background analysis is indispensable. Take business English for example, introduction to the domestic air-conditioner trade can come before analysis of characteristic of the development of the distribution channel in China, and then figure out the tendency of distribution channel. In addition, there is an increasing demand for talents in EOP with the booming of one belt and one road.

It is believed experiential learning is of great benefit to students. Classroom is not merely a place to learn theory, but one to experience what they learn from the book. Take business English for instance, simulation of fairs in class is necessary and vital by which students know how fairs are operated and what business is dealt with. Besides learning in classroom, if possible, students are guided to attend real fairs such as China Import and Export Fair, Car Fair and Housing Fair. While in-person participation in fairs may be no easy task for school, school and teachers should spare no efforts to offer video on a variety of fairs for students to experience second-hand materials if first hand ones are not available.

Opportunities are created for students to exercise themselves[9]. In other words, colleges are supposed to try every means to keep in touch with firms, factories and enterprises. EOP courses aim to improve students' practical ability. Therefore, authentic working situations and occasions are ideal for students to apply what they in class into reality. In this way can students' professional ability be greatly improved. School authorities are supposed to provide opportunities for students to practice in the related firms, factories and enterprises.

Experts in related fields are invited to make a speech or report on related occupations in the university[10]. Teachers are expected to cooperate with experts in the university. The way of cooperation can be negotiated by school authorities and enterprises. It can be mutual teaching or mutual preparing of teaching plan. Experts or professionals from firms or enterprises can participate in teaching namely give a lecture to students. They are able and expected to participate in the design of teaching purpose and plan with requirement of enterprises considered in order to cultivate talents desirable to job market.

Majors and courses relevant to occupations are expected to vary, increase or decrease, with the demand of society. Teachers, textbook, teaching content, teaching facilities, teaching methods and plan are to adapt to the change of society. Efforts can be made to establish projects or programs for students to do with the help of teachers and enterprises. The more interaction there are between enterprises and schools, the more benefits students will reap. In other words, enterprises and school cooperate to cultivate talents capable and suitable for future demand. Fund and location of practice are offered by enterprises while school is mainly in charge of teaching. It is agreed in the contract signed by schools and enterprises graduates can be employed by enterprises concerned once they satisfy the requirements of enterprises. Enterprises concerned hold priority to hire qualified graduates or graduates must serve enterprises concerned for a period of time based upon agreement. 


\section{Conclusion}

The teaching of EOP should not be isolated or constrained in the ivory tower of college but keep in pace with the development of society and the demand of job market. School and teachers are expected to be open to a variety of teaching resources and make full use of resources available by enhancing various cooperation with enterprises in order to cultivate qualified talents for job market. Objectively speaking, the teaching and learning of EOP are driven by market demand and requirements of country development. Satisfying market demand and requirement of society are the goals that schools should strive to achieve. This will in return facilitate the booming of related majors, earning reputation for schools.

\section{Acknowledgements}

This work was financially supported by Hubei Provincial Department of Education (201701060).

\section{References}

[1] Cai Jigang. Development and Prospects of ESP [J]. Journal of Xi'an International Studies University2015 (1):68-72. (In Chinese)

[2] Cai Jigang. ESP in China: Yesterday, Today and Tomorrow [J]. Journal of University of Shanghai for Science and Technology2016 (2):106-113.(In Chinese)

[3] Cai Jigang. The Implication of the Shift from EGP to ESP in National Cheng Kung University, Taiwan [J]. Foreign Language Learning Theory and Practice 2013 (3): 94 -99. (In Chinese)

[4] Cai Jigang. Zero distance approach to the integration of the national requirements with the undergraduates' foreign language capacity in the perspective of individualized instruction and individual needs [J]. Journal of Yunnan Normal University 2016 (3):33-39. (In Chinese)

[5] Wen Qiufang Satisfying students' needs is the goal of English teaching [N] China Education 2008(5). (In Chinese)

[6] Song, B. Content-based ESL instruction: Long-term effects and outcomes [J]. English for Specific Purposes 2006 (25): 420-437.

[7] Paran. A. CLIL: Content and Language Integrated Learning [J]. ELTJ 2013(1):137-141.

[8] Messick, S. Validity [A].In R. L. Linn(ed.)Educational Measurement(3rd edition) [C]. New York: Macmillan, 1989.

[9] R Kumar, B Refaei. Designing a Problem-based Learning Intermediate Composition Course [J]. College Teaching, 2013, 61(2).

[10] Ding Houyin. The integration of CBI and action research [J].Foreign Languages and their Teaching, 2009(3). (In Chinese) 